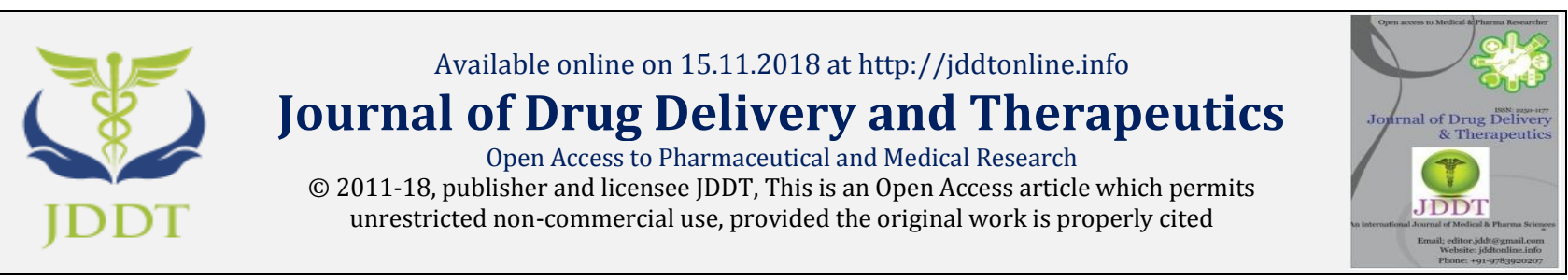

Open $\odot$ Access

Research Article

\title{
In-vitro cytotoxicity of java tea mediated selenium nanoballs against L6 cell lines
}

\author{
Chitra Sivakumar ${ }^{*}$, Karthikeyan Jeganathan ${ }^{2}$ \\ ${ }^{1}$ Research Scholar, Research and Development Centre, Bharathiar University, Coimbatore, India \\ 2 Associate Professor and Head, Department of Biochemistry, (PG and Research) Kongunadu Arts and Science College, (Autonomous), \\ Coimbatore, India
}

\begin{abstract}
The emergence of Nanotechnology has provided a catholic research in recent years by intersecting with assorted branches of science and forming collision on all forms of life. At present there has been a prodigious excitement in the field of Nano pharmacology to seek the role of Nano selenium in individual healthcare and explains how selenium is a double edged sword in the pathologies of chronic diseases like Diabetes mellitus because of their inferior toxicity and ability to gradually release the bioactive principle and free selenium after ingestion. Thus the present study is an embryonic attempt and was aimed at the adroitful synthesis of selenium nanoballs from the aqueous extract of well known herbal tea leaves namely Java tea (Orthosiphon stamineus) using selenious acid solution. The synthesized Selenium nanoparticles were then subjected to various characterization techniques such as UV, FTIR, FESEM, EDAX and Zeta potential respectively. Finally the green synthesized SeNps were tested for their cytotoxic effect against L6 rat skeletal muscle cell lines. The pre clinical studies are underway to prove the insulin mimic activity of the selenium nanoparticles.
\end{abstract}

Keywords: Selenium Nanoparticles, Java tea, L6 cell lines.

Article Info: Received 03 Oct, 2018; Review Completed 06 Nov 2018; Accepted 09 Nov 2018; Available online 15 Nov 2018

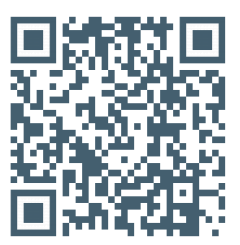

\section{Cite this article as:}

Chitra Sivakumar, Karthikeyan Jeganathan, In-vitro cytotoxicity of java tea mediated selenium nanoballs against L6 cell lines, Journal of Drug Delivery and Therapeutics. 2018; 8(6):195-200 DOI: http://dx.doi.org/10.22270/jddt.v8i6.2046

\section{*Address for Correspondence:}

Chitra Sivakumar, Research Scholar, Research and Development Centre, Bharathiar University, Coimbatore, India. Email: dhanuchitra@gmail.com

\section{INTRODUCTION}

The field of Nanotechnology devours great enthusiasm in recent years because of its anticipated impact on science, industry, economy and our everyday life. Today nanoparticles of both metallic and non metallic origin are under research and development in various fields of biology and therapeutics 1. Due to the inimitable characteristics exhibited by nanoparticles, they are employed in nanomedicine and nanotherapeutics which are the supreme aspects of nanotechnology to be implemented in human health.

Metal nanoparticles are vital part of future nanotherapeutics which has wide-ranging applications in diverse areas such as chemistry, physics, and biomedical and material sciences ${ }^{2}$. They have tremendous applications in the area of catalysis, optoelectronics, diagnostic biological probes and display devices ${ }^{3}$. Production of nanoparticles can be achieved through conventional chemical methods and physical methods ${ }^{4,5}$. While chemical approaches are the most popular methods for the production of nanoparticles some chemical methods cannot avoid the use of toxic chemicals in the synthesis protocol. Engaging plants in the synthesis of nanoparticles has drawn more interest of workers because it provides single step biosynthesis process, can be advantageous over other biological processes by eliminating the elaborate process of maintaining cell culture ${ }^{6}$. Plants also tender a superior option for synthesis of nanoparticle, as the protocols involving plant sources are free from toxicants; furthermore, natural capping agents are readily supplied by the plants. Selenium (Se), belonging to group 16 of the periodic table is well known for its photoelectric and semiconductor properties. These nanoparticles show biological activity and good adsorptive ability due to interaction between the nanoparticles and $\mathrm{NH}, \mathrm{C} \mathrm{O}, \mathrm{COO}-$ and $\mathrm{C} N$ groups of proteins ${ }^{7}$. Selenium nanoparticles have also been developed for applications in medical diagnostics ${ }^{8}$. Thus selenium nanoparticles caused the great interest of researchers and a variety of synthesis methods have been exploited ${ }^{9}$. 
Biogenic synthesis of Se nanoparticles is frequently achieved by reduction of selenate/selenite in presence of bacterial proteins or plant extracts containing phenols, flavonoids amines, alcohols, proteins and aldehydes. Very few studies have been reported the synthesis of selenium nanoparticles using higher plants. The biomaterials of higher plants used for the synthesis of selenium nanoparticles were Capsicum annum ${ }^{10}$, dried raisin extract $^{11}$, leaves of lemon ${ }^{12}$, Terminaliaarjuna ${ }^{13}$ and seed extract of fenugreek ${ }^{14}$, flower broth of Catharanthu sroseus $^{15}$, Flower of Bougainvilleaspectabilis ${ }^{16}$ in the synthesis of selenium nanoparticles. In the present study Orthosiphon stamineus Benth which is a popular traditional folk medicine is selected for synthesising selenium nanoparticles for the first time as an maiden attempt. It is used in Indonesia for rheumatism, diabetes, hypertension, tonsillitis, epilepsy, menstrual disorders, gonorrhea, syphilis, renal calculus and gallstones; in Vietnam for urinary lithiasis, edema, eruptive fever, influenza, hepatitis, jaundice and biliary lithiasis; and in Myanmar to alleviate diabetes and urinary tract and renal diseases $17-21$. Phytochemical studies 22,23and Pharmacological studies 24 of this plant have been conducted since many years. study Thus the present investigation is aimed to evaluate the ability of bioreductive potential of the aqueous leaf extract of Orthosiphon stamineus in the synthesis of selenium nanoparticles and also evaluated the cytotoxicity of selenium nanoparticles against L6 rat skeletal muscle cell lines.

\section{MATERIALS AND METHODS}

\subsection{Collection of Plant Material}

The fresh plant of (Orthosiphon stamineus) was collected and was authenticated by Dr. S. Sahaya Sathish, Associate Professor, Department of Botany, St. Joseph's College, Trichy. Dried Java tea leaves were purchased from Organic farm, Salem and was used as the sample for the biosynthesis of the Selenium nanoparticles.

\subsection{Preparation of Extract}

The dried leaves were blended using a blender and the powder was stored in a clean glassware container for further analysis.50 gms of powdered leaves were mixed in $300 \mathrm{ml}$ of distilled water in a clean beaker and was stored in a glass container. The contents were mixed by stirring for 15 minutes. It was kept undisturbed for overnight after 24 hours the mixture was then filtered using filter paper (whatman no1).The filtrates were then used for further assay. The aqueous extract of the leaves were screened qualitatively for the presence of secondary metabolites using the routine phytochemical analysis.

\subsection{Synthesis of Selenium Nanoparticles}

For the green synthesis of selenium nanoparticles, $1 \mathrm{ml}$ of plant extract was mixed with $10 \mathrm{ml}$ of $30 \mathrm{mM}$ selenious acid solution along with 200 ul of $40 \mathrm{mM}$ ascorbic acid which was used as an initiator of reduction reaction. Standard positive control was maintained using $1 \mathrm{ml}$ of $0.2 \%$ sodium alginate $+10 \mathrm{ml}$ of $30 \mathrm{mM}$ selenious acid and $200 \mathrm{ul}$ of $40 \mathrm{mM}$ ascorbic acid for the synthesis of selenium nanoparticles. $1 \%$ Orthosiphon leaf extract $+200 \mu \mathrm{l}$ of $40 \mathrm{mM}$ ascorbic acid was used as negative control 16 . The preparations were incubated at room temperature. After $24 \mathrm{hrs}$ of incubation the preparation was centrifuged at $10000 \mathrm{rpm}$ for 30 minutes. The pellet was washed with double distilled water and then with absolute alcohol three times. This washed ethanol pellet was dried overnight. The red selenium nanoparticles were suspended in PBS $\mathrm{CH}$ -
7.4) by ultra sonication and then centrifuged. The powder form of the extract was used for further analysis.

\subsection{Characterization of Nanoparticles}

The formation of selenium nanoparticles was confirmed by the visual observation. The synthesized SeNps were analyzed for the rate of absorption by using UV-Visible spectrometer. The UV- Visible spectral study was done in the range of 200 to $400 \mathrm{~nm}$. FT-IR measurements was carried out for the synthesized SeNps to identify the possible bioactive molecules responsible for the reduction of the selenium and the capping ability of the bio reduced selenium nanoparticles by the aqueous leaf extract of $O$. Stamineus using $\mathrm{KBr}$ pellets and the spectra was recorded in the wavelength interval 4000 to $400 \mathrm{~cm}$-.The FESEM and EDAX analysis revealed average shape, size and elemental composition of the synthesized SeNps. The charge distribution of selenium nanoparticles was confirmed with zeta potential analysis.

\subsection{In-vitro Cytotoxicity Analysis}

\section{MTT assay}

The monolayer cell culture of L6 rat skeletal muscle cell lines was trypsinized and the cell count was adjusted to 1.0 x $10^{5}$ cells/ml using respective media containing $10 \%$ FBS. To each well of the 96 well micro titer plates, $100 \mu \mathrm{l}$ of the diluted cell suspension (50,000cells/well) was added. After $24 \mathrm{~h}$, when a partial monolayer was formed, the supernatant was flicked off, washed the monolayer once with medium and $100 \mu \mathrm{l}$ of different test concentrations $(10,20,40,80,160,320 \mu \mathrm{g} / \mathrm{ml})$ of selenium nanoparticles were added on to the partial monolayer in micro titer plates. The plates were then incubated at $37^{\circ} \mathrm{C}$ for $24 \mathrm{hrs}$ in $5 \% \mathrm{CO}_{2}$ atmosphere. After incubation the test solutions in the wells were discarded and $100 \mu \mathrm{l}$ of MTT $(5 \mathrm{mg} / 10 \mathrm{ml}$ of MTT in PBS) was added to each well. The plates were incubated for $4 \mathrm{~h}$ at $37^{\circ} \mathrm{C}$ in $5 \% \mathrm{CO}_{2}$ atmosphere. The supernatant was removed and $100 \mu \mathrm{l}$ of DMSO was added and the plates were gently shaken to solubilize the formed formazan. The absorbance was measured using a micro plate reader at a wavelength of $590 \mathrm{~nm}$. The percentage of cell viability was calculated using the following formula.

$\%$ Cell Viability= 100-(OD of sample/OD of Control) $\times 100$.

\section{RESUTS AND DISCUSSION}

\subsection{Bioactive profiling of Aqueous extracts $(O$. Stamineus)}

Table 1: Phytochemical screening of Aqueous extract of O.stamineus

\begin{tabular}{|l|c|}
\hline \multicolumn{1}{|c|}{ TEST } & AQUEOUS EXTRACT \\
\hline ALKALOIDS & ++++ \\
\hline FLAVONOIDS & ++++ \\
\hline STEROIDS & + \\
\hline CARDIAC GLYCOSIDES & + \\
\hline TERPENOIDS & + \\
\hline TANNINS & +++ \\
\hline SAPONINS & ++ \\
\hline REDUCING SUGAR & + \\
\hline ANTHRAQUINONE & ++ \\
\hline PHENOL & ++++ \\
\hline CARBOHYDRATES & ++ \\
\hline
\end{tabular}

Bioactive profiling was performed in aqueous extract of o.Stamineus leaves. The phytochemical screening showed the presence of alkaloids, flavonoids, amino acids and 


\section{Chitra et al}

protein, carbohydrate, cardiac glycosides and saponins in aqueous extract of Java tea leaves (Table-1). It is rich in flavanoids, terpenoids and other secondary metabolites having reducing functional groups which might have played a role in reducing selenious acids to SeNPs. $O$. stamineus has wide traditional and pharmacological uses in

\subsection{Visual Observation}

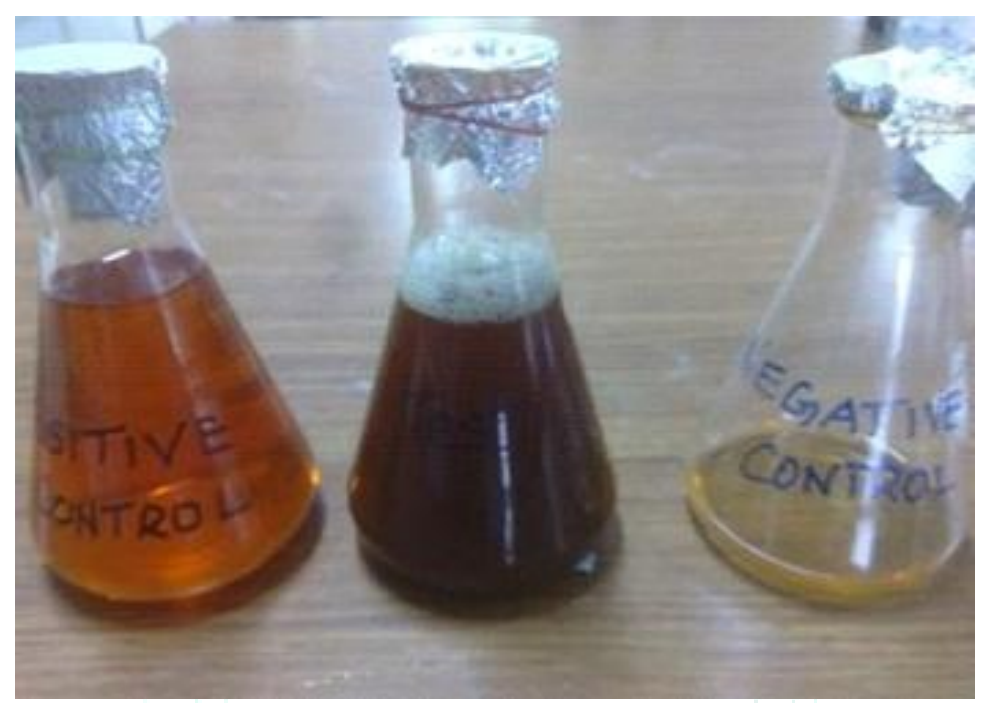

Figure 1: Visual Observation of Formation of SeNps

The bio reduction of the selenious acid using aqueous leaf extract of 0 . stamineus was monitored and the appearance of brownish orange colour indicates the formation selenium nanoparticles. Initially the plant extract was light brown in colour. But after the addition of colourless various pathophysiological conditions. It has been shown that plant extract containing phenol and flavonol derivatives act as reducing agents and nanoparticle stabilizer. FTIR spectrum of java tea extract shows the presence of various functional groups (Figure-3)

\subsection{UV-Visible spectroscopy}

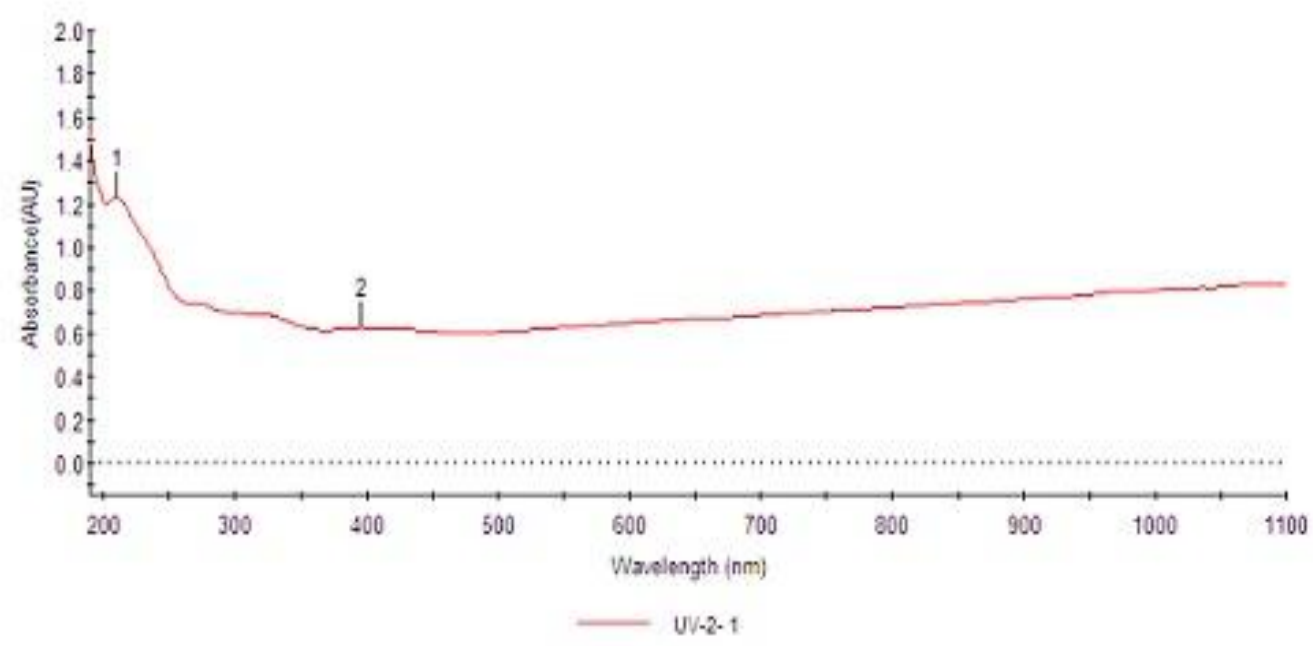

Figure 2: UV-Vis Spectra of Se Nanoparticles Synthesized by Using Java tea leaf Extract

The above (Figure-2) shows the UV-Vis Spectra of the asformed SeNps exhibiting the maximum absorption peak at about $209 \mathrm{~nm}$. This is due to the surface plasmon resonance of selenium nanoparticles. The red color of the selenious acid solution the colour gradually changes from light brown to dark brownish orange as shown in the (Figure-1).The appearance of brownish orange colour indicates the reduction of selenious acid and formation of SeNps similar to the results reported earlier ${ }^{16}$. 


\subsection{Fourier Transform Infrared Spectroscopy (FTIR) analysis}

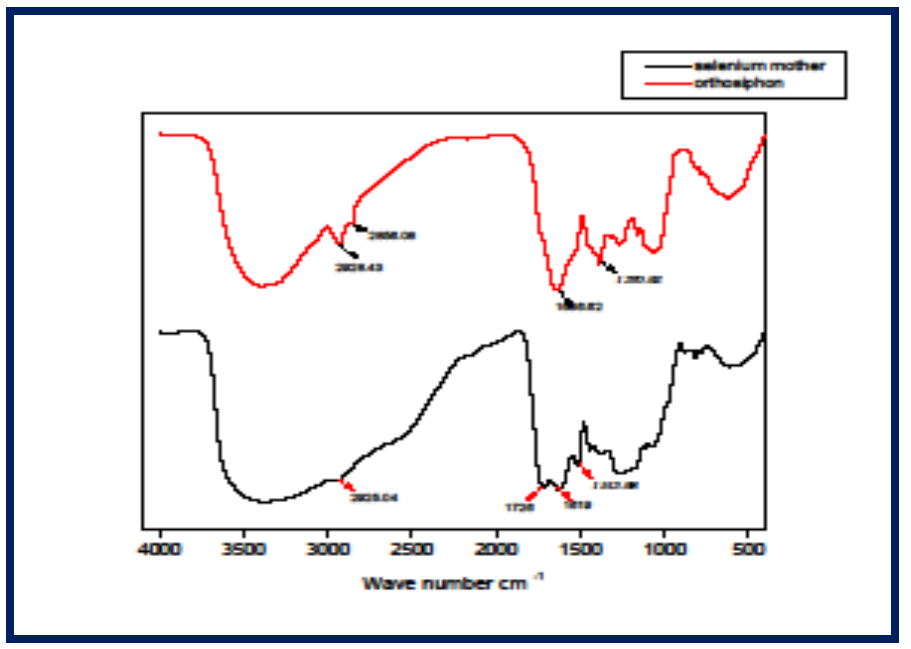

Figure 3: FTIR Spectrum of the aqueous leaf extract and SeNps

FTIR measurements of both the aqueous java tea leaves extract and the synthesized dried SeNps were carried out to identify the possible biomolecules responsible for the reduction, capping and efficient stabilization of the bio reduced SeNps. The FTIR spectra of both the leaf extract as well as SeNps are shown in (Figure-3). The aqueous Java tea leaf extract displays a number of absorption peaks reflecting its complex nature. The spectrum was recorded in the wavelength region between $400 \mathrm{~cm}-1$ to $4000 \mathrm{~cm}-1$. The spectrum of aqueous Java tea leaves extract shows the peaks at wave numbers $3388 \mathrm{~cm}-1,2928 \mathrm{~cm}-1,2856^{\mathrm{cm}-1}, 1637$ $\mathrm{cm}-1,1385 \quad \mathrm{~cm}-1,1321 \quad \mathrm{~cm}-1,1265 \quad \mathrm{~cm}-1,1158 \quad \mathrm{~cm}-1,1069 \quad \mathrm{~cm}-1$ respectively. The broad peak at 3388 was due to the presence of alcohol (O-H) stretching of Phenolic compound. The peak at $2928 \mathrm{~cm}-1$ and $2856^{\mathrm{cm}-1}$ showed a sharp peak and strong alkane $\mathrm{C}-\mathrm{H}$ stretching. The peak at $1636^{\mathrm{cm}-1}$ and $1384^{\mathrm{cm}-1}$ showed a variable alkene $\mathrm{C}=\mathrm{C}$ and alkane $(\mathrm{C}-\mathrm{H})$

\subsection{FESEM and EDAX analysis}

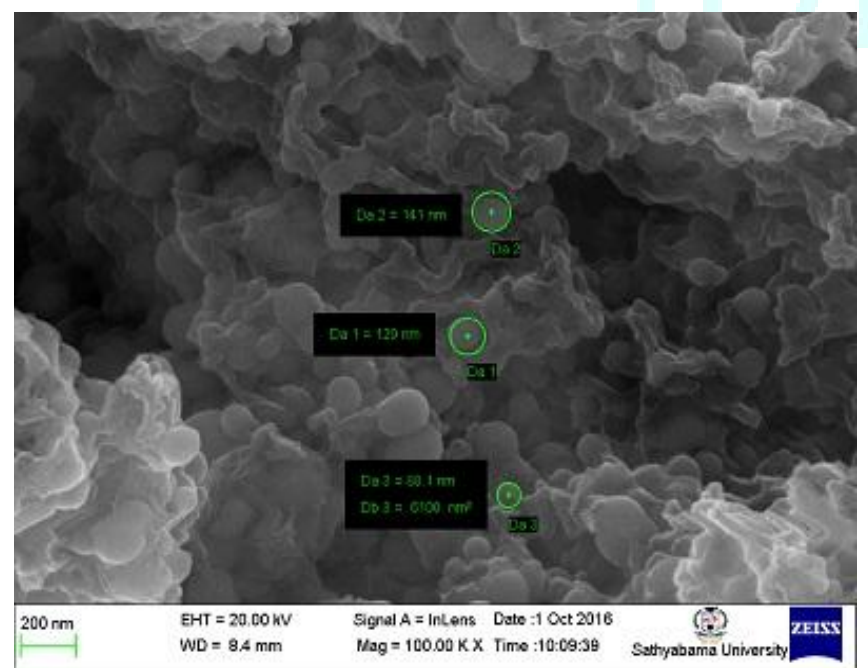

stretch. The other peaks at $1265 \mathrm{~cm}-1,1158 \mathrm{~cm}-1,1069 \mathrm{~cm}-$ ${ }^{1}$ were due to amine $(\mathrm{C}-\mathrm{N})$, ether, alkene, C-Cl sretching. After the reduction process the absorption peaks at 3381 $\mathrm{cm}-1,2960 \mathrm{~cm}-1,1718^{\mathrm{cm}-1}, 1629 \mathrm{~cm}-1,1516^{\mathrm{cm}-1}$ were observed as shown in (Figure-3).Corresponds to alcohol(O-H), alkene $(\mathrm{C}-\mathrm{H})$, carbonyl $(\mathrm{C}=\mathrm{O})$, alkene $\mathrm{C}=\mathrm{C}$ and aromatic $\mathrm{C}=\mathrm{C}$ stretching of Phenolic compound. The peaks at $2928 \mathrm{~cm}-1$ and $2856 \mathrm{~cm}-1$ were disappeared and shifted to $2960 \mathrm{~cm}$ 1.The peak corresponds to alkene $\mathrm{C}=\mathrm{C}$ was disappeared and shifted to $1718^{\mathrm{cm}-1}$. A sharp peak at $1384^{\mathrm{cm}-1}$ was disappeared and was shifted to $1441^{\mathrm{cm}-1}$ corresponds to aromatic $\mathrm{C}=\mathrm{C}$ stretch. Based on the above observations it is inferred that the biosynthesized SeNps might be surrounded by any one of these organic molecules such as polyphenols, alkaloids, terpenoids which are in accordance with the facts already reported in the earlier reports ${ }^{16}$.

Figure 4: FESEM Analysis of Selenium nanoparticles

The surface morphology and size of the nanoparticles were obtained by Frontier Scanning Electron Microscopy analysis. The above (Figure-4) shows the SeNPs

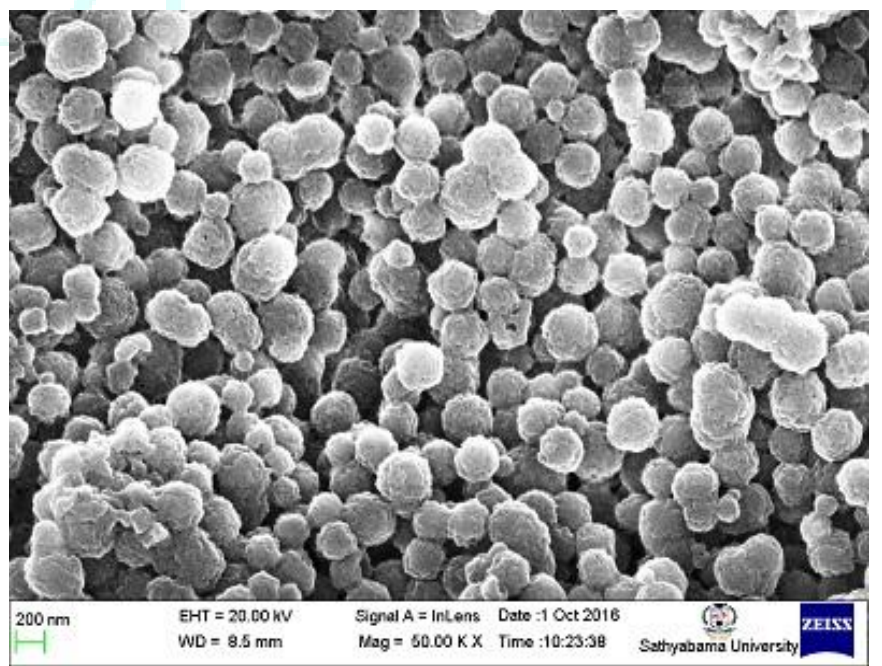

synthesized by the Java tea leaves extract. The electrostatic interactions and hydrogen bond between the bio-organic capping molecules bond are responsible for the synthesis 
of selenium nanoparticles using plant extract. The image clearly indicates the spherical nature of the selenium nanoparticles as shown in the above figure and they merely look like balls. The relatively uniform shape of the SeNps was confirmed in the range of $88 \mathrm{~nm}-141 \mathrm{~nm}$. The obtained results were also supported in the earlier studies.
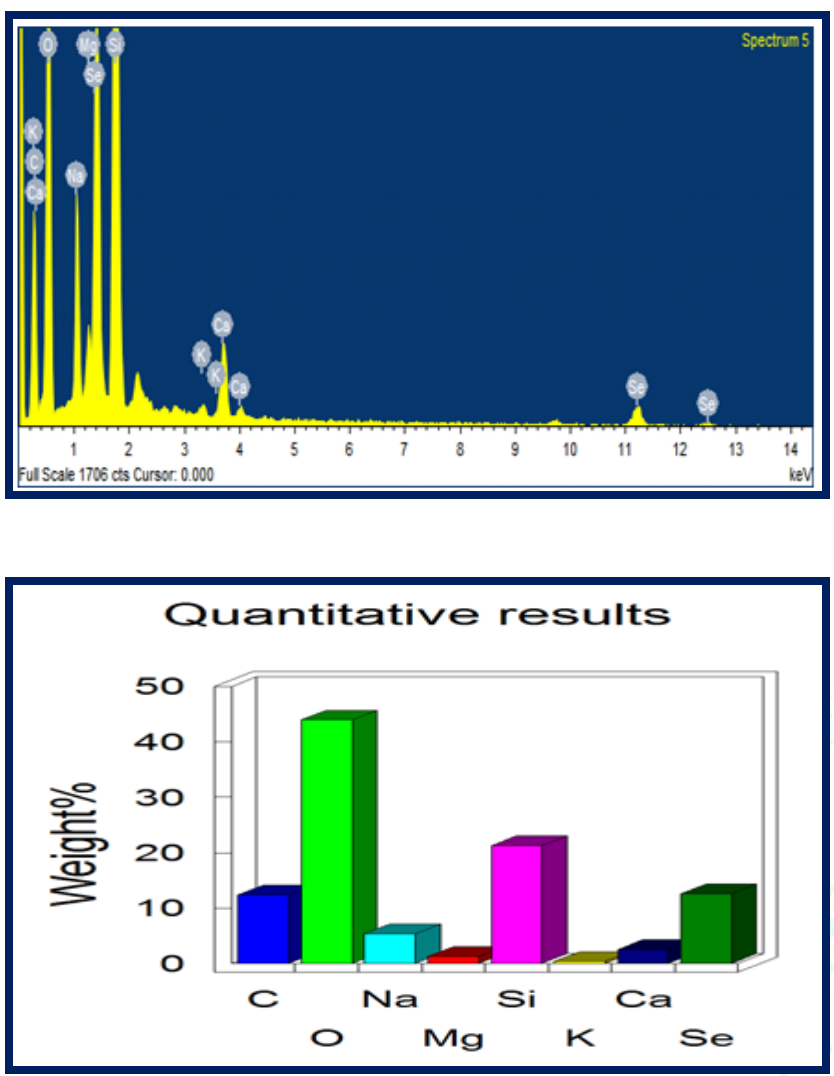

Figure 5: Edax Spectrum of SeNps
An elemental composition analysis employing FESEMEDAX showed the presence of a strong signal from Se atoms (12.62\%) (Figure-5). This analysis indicated that the nanostructures were composed of selenium. Other EDAX peaks such as $\mathrm{C}, \mathrm{K}, \mathrm{Na}, \mathrm{Mg}$, $\mathrm{O}$, Si were also found, suggesting that they were mixed precipitates of the selenium salt.

\subsection{Zeta potential value of Selenium Nanoparticles:}

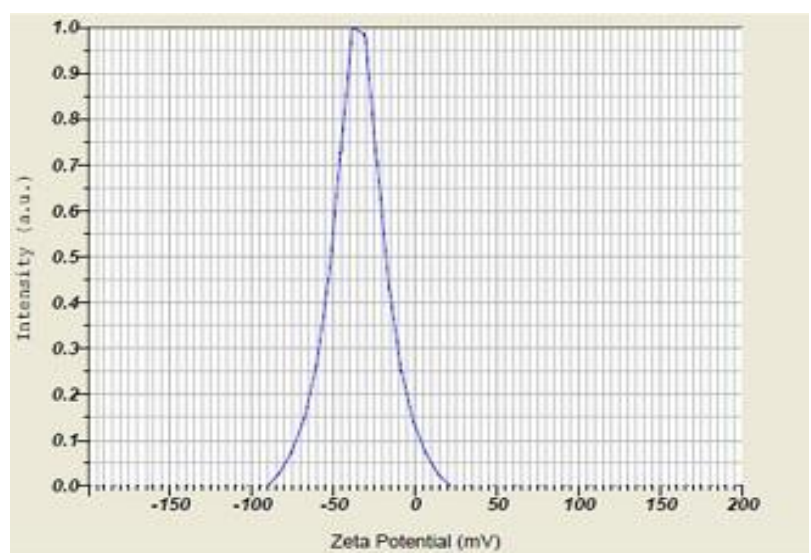

Figure 6: Zeta Potential of SeNps

The zeta potential measurements indicate negative charge $(-34.9 \mathrm{mV})$ on the selenium nanoparticles as shown in the above (Figure-6). If all the particles in suspension have a negative or positive zeta potential, then they will tend to repel each other and there is little tendency for the particles come together. The slightly negative charge on Se particles is probably resulting in the high stability of the selenium nanoparticles without forming aggregates and these particles do not transform to black amorphous form when kept for prolonged period of time of more than a month.

\subsection{MTT Assay}

Table 2: MTT Assay

\begin{tabular}{|c|c|c|c|}
\hline \multicolumn{4}{|c|}{ L6 cell lines } \\
\hline Compound name & Conc. $\boldsymbol{\mu g} / \mathbf{m l}$ & OD at 590nm & \% Cell viability \\
\hline Control & 0 & 0.596 & 0 \\
\hline SeNp & 10 & 0.574 & 3.76 \\
\hline \multirow{5}{*}{} & 20 & 0.543 & 8.95 \\
\cline { 2 - 4 } & 40 & 0.502 & 15.83 \\
\cline { 2 - 4 } & 80 & 0.456 & 23.54 \\
\cline { 2 - 4 } & 160 & 0.422 & 29.24 \\
\cline { 2 - 4 } & 320 & 0.387 & 35.11 \\
\hline
\end{tabular}

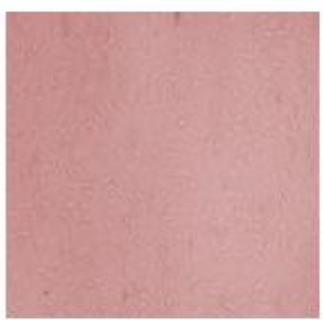

Test-10 $\mu \mathrm{g}$

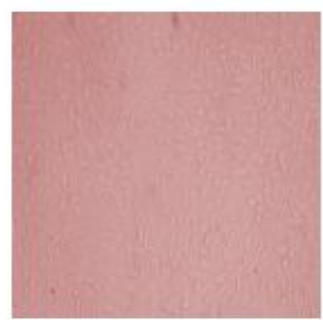

Test-320 $\mu \mathrm{g}$

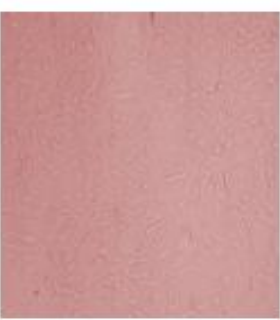

Control

Figure 7: Invitro Cytotoxicity of Selenium nanoparticles

Thus the successfully synthesized SeNp was screened for the cytotoxicity against L6 Cell lines by MTT Assay. From the above Table-2, it was understood that the optical density decreases as the concentration of selenium nanoparticles increases, indicating the increase in cell viability. Thus the L6 rat skeletal muscle cells showed 
nontoxic effect and the \% of cell viability was notably increased. These results clearly demonstrate that the phytochemicals within these herbs provide nontoxic coating on SeNPs and corroborate the results of the internalization studies discussed above. The lack of any noticeable toxicity of Java tea mediated selenium nanoparticles provides new opportunities for the safe application in molecular imaging and therapy.

In modern science, biomedical technology is well developed and growing in recent times. Biological synthesis of metal nanoparticles is an important role in the field of modern nanotechnology. Green synthesis of nanomedicine plays key role in bio Medical science. In this study, biological synthesis of selenium using java tea leaves and their cytotoxic study is taken into consideration. The nanoparticles obtained are characterized by UV-spectral analysis, FESEM, EDAX, Zeta potential. The functional groups of the selenium nanoparticles in Java tea leaves extract were characterized by Fourier Transform Infrared Spectroscopy. The in vitro cytotoxicity analysis of selenium nanoparticles showed good cell viability against L6 rat skeletal muscle cell line. From this study, it is found that the biomedical properties are present in Selenium nanoparticles.

\section{CONCLUSION}

In the present study, selenium nanoballs were successfully synthesized using the plant extract of Orthosiphon stamineus. The synthesized nanoparticles were found to increase the cell viability in L6 cell lines. The preclinical studies for treating diabetes mellitus and to prove the insulin mimic activity of selenium nanoparticles are underway. Thus the green synthesized nanoparticles were found to be cost-effective, simpler, and environmentally safe. As the nanotechnology is an emerging field in medicine, the biological synthesis of nanoparticles helps in the other way. In Future, it is a promising contender for various clinical applications in a safe and ecofriendly manner.

\section{ACKNOWLEDGEMENT}

The authors would like to thank Dr. R. Rajamurugan (late) for his valuable guidance, and also grateful to Dr. S. Sahaya Sathish, Associate Prof., Dept. of Botany, St. Joseph college, Trichy, Dr. C. Narendhar, Assistant Prof., Dept. of Nano Science and technology, Sri Ramakrishna Engineering College, Coimbatore, Shri. G. Arihara Sivakumar, Associate Prof., Dept. of Pharmacology, KMCH College of Pharmacy, Coimbatore, Shri. D. Ramachandran, Scientist -C, Centre for Nano science and technology, Sathyabama University, Chennai for their technical assistance and support.

\section{REFERENCES}

1. Sengupta J, Ghosh S, Datta P, Gomes A. Gomes A. Physiologically Important Metal Nanoparticles and Their Toxicity. J. Nanosc. Nanotechnol, 2014; 14(1):990-1006.

2. Prasad KS, Pathak D, Patel A, Dalwadi P, Prasad R, Patel P, Selvaraj K.P. Biogenic synthesis of silver nanoparticles using Nicotiana tobaccum leaf extract and study of their antibacterial effect. Afr.J. Biotechnol, 2011; 10: 8122.

3. Sathishkumar G, Gobinath C, Karpagam K, Hemamalini V, Premkumar K, Sivaramakrishnan S, Phyto-synthesis of silver nanoscale particles using Morinda citrifolia L. and its inhibitory activity against human pathogens.Colloids Surf, 2012; B 95:235.

4. Murray CB, Kangan CR, Bawendi MG.Synthesis and characterization of monodisperse nanocrystals and close- packed nanocrystal assemblies. Annu. Rev. Mater. Sci. 2000; 30:545.

5. Ayyub P, Chandran R, Taneja RP, Sharma A, Pinto R. Synthesis of nanocrystalline material by sputtering and laser ablation at low temperature. Appl. Phys. A, 2001; 73:67.

6. Ren F, He X, Wang K, Yin JJ. Biosynthesis of gold nanoparticles using Catclaw Buttercup (Radix Ranunculi Ternati) and evaluation of its colloidal stability, Biomed.Nanotechnol, 2012; 8:586.

7. Zhang Y, Zhang J, Wang HY, Chen HY. Synthesis of selenium nanoparticles in the presence of polysaccharides. Lett, 2004; 58: 2590.

8. Yost DA, Russel JC, Yang H, Evidence on the size-dependent absorption spectral evolution of selenium nanoparticles U.S. Patent 4954452 (1990).

9. Sasidharan S, Balakrishnaraja R. Comparison studies on the synthesis of selenium nanoparticles by various microorganisms.Int. J. Pure. Appl. Biosci, 2014; 2:112-117.

10. Li, Shen SK, Xie YH, Yu AJ, Zhang XR, Yang XZ, Li LB, Rapid, room-temperature synthesis of amorphous selenium/protein compositesusing Capsicum annuumL. extract.Nanotechnol, 2007; 18:405101-405109.

11. Sharma G, Sharma AR, Bhavesh R, Park J, Ganbold B, Nam J, Lee $\mathrm{S}$. Biomolecule-mediated synthesis of selenium nanoparticles using dried Vitisvinifera (raisin) extract. Molecules.2014; 19:2761-2770.

12. Prasad KS, Patel H, Patel T, Patel K, Selvaraj K. Biosynthesis of Se nanoparticles and its effect on UV-induced DNA damage.Colloids Surf. B. Biointerfaces, 2013; 103:261-266.

13. Prasad KS, Selvaraj K, Biogenic synthesis of selenium nanoparticles and their effect on As(III)-induced toxicity on human lymphocytes. Biol Trace Elem Res, 2014, 157:275283.

14. Ramamurthy CH, Sampath KS, Arunkumar P, Kumar M.S, Sujatha V, Premkumar K, Thirunavukkarasu C. Green synthesis and characterization of selenium nanoparticles and its augmented cytotoxicity with doxorubicin on cancer cells. Bioprocess Biosyst Eng, 2013; 36:1131-1139.

15. Ganesan V, et al., Bioinspiredsynthesis of selenium nanoparticles using flowers of Catharanthus roseus(L.) G.Don.and Peltophorum pterocarpum(DC.)Backer ex Heyne a comparison. Int.J. ChemTech Res. 2015; 7(2):725-733

16. Ganesan V. Biogenic synthesis and characterization of selenium nanoparticles using the flower of Bougainvillea spectabilis Willd. Int J Sci Res, 2015; 4:690-695.

17. Chin JH, Abas HH, Sabariah I. Effect of Orthosiphon stamineus leaf extracts on hepatic cytochrome P450, UGT and GST activity in STZ-induced diabetic rats. J Adv Sci Arts 2009; 1:18.

18. Suresh A, Yasuhiro T, Arjun H, Banskota S, Shimoji KT, Shigetoshi K. Siphonols A-E: Novel Nitric Oxide Inhibitors from Orthosiphon stamineus of Indonesia. Bioorg Med Chem Lett 2003; 13:31-35.

19. Bwin DM, Gwan US. Ministry of Health, Health and Myanmar traditional medicine. In: Burmese Indigenous Medicinal Plant: 1. Plants with reputed Hypoglycemic Action; Burma Medical Research Institute: Yangon, Burma, 1967; 126-28.

20. Eisai PT. Indonesia Medicinal Herb Index in Indonesia, 2nd ed. University Press: Godjah Mada, 1995: 239-263.

21. Tran K. WHO Regional Office for the Western Pacific Manila and Institute of Material Medica Hanoi, in Medicinal Plants in Vietnam; Science and Technology Publishing House: Hanoi, Vietnam 1970.

22. Dhanjal S, Cameotra SS. Aerobic biogenesis of selenium nanospheres by Bacillus cereus isolated from coalmine soil. Microbial Cell Factories, 2010; 9:52-61.

23. Oremland RS, Herbal MJ, Blum JS, Langely S, Beveridge TJ, Ajayan PM, Sutto T, Ellis AV. Structural and Spectral Features of Selenium Nanospheres Produced by Se-Respiring Bacteria,Appl. Environ. Microbiol, 2004; 70:52.

24. Doan DD, Nguyen NH, Doan HK. Studies on the individual and combined diuretics effects of four Vietnamese traditional herbal remedies (Zea mays, Imperata cylindrica, Plantago major and Orthosiphon stamineus). J Ethnopharmacol, 1992; 36(3):225-231. 